\title{
Hepatic inflammatory pseudotumour-like follicular dendritic cell tumor: A case report
}

\author{
XUDONG ZHANG, CHUNFU ZHU, YUTING HU and XIHU QIN \\ Department of General Surgery, The Affiliated Changzhou No. 2 People's Hospital \\ of Nanjing Medical University, Changzhou, Jiangsu 213000, P.R. China
}

Received November 9, 2016; Accepted January 11, 2017

DOI: $10.3892 / \mathrm{mco} .2017 .1188$

\begin{abstract}
Hepatic inflammatory pseudotumor (IPT)-like follicular dendritic cell (FDC) tumor is a rare neoplasm. We herein report the case of 19 -year-old female patient with an IPT-like FDC tumor and summarize 24 cases of hepatic FDC tumors previously reported in the English literature. The patient presented with complaints of abdominal discomfort, without significant laboratory abnormalities, and underwent surgical removal of a hepatic tumor. The resected tumor was $6 \mathrm{~cm}$ in the longest diameter and the tumor cells were positive for CD21, CD35 and Epstein-Barr virus (EBV). The postoperative course was uneventful and there have been no metastases or recurrence during 1 year of follow-up. The majority of the cases of hepatic IPT-like FDC tumors have a female predominance and exhibit an association with EBV infection. Their clinical manifestations and image findings are usually non-specific and the diagnosis of this disease mainly relies on pathology.
\end{abstract}

\section{Introduction}

Follicular dendritic cells (FDCs) are an accessory part of the lymphoid system and their function is to present antigens to specialized lymphocytes (1). In the liver, FDCs are distributed around portal spaces, and the probability of them forming tumors is quite small. According to the World Health Organization classification in 2001 and 2008, inflammatory pseudotumor (IPT)-like FDC tumor was considered to be a distinct variant of low-grade FDC tumor/sarcoma (2). This tumor is characterized by a lymphoplasmacytic infiltrate mixed with neoplastic spindle cells, forming an inflammatory pseudotumor (3). Due to the low incidence and our limited

Correspondence to: Dr Xihu Qin, Department of General Surgery, The Affiliated Changzhou No. 2 People's Hospital of Nanjing Medical University, 29 Xinglong Lane, Changzhou, Jiangsu 213000, P.R. China

E-mail: zxd26244@126.com

Key words: follicular dendritic cell tumor, hepatic neoplasms, inflammatory pseudotumour, CD21, Ebstein Barr virus experience with the disease, IPT-like FDC tumor in the liver may not be included in the differential diagnosis during the initial evaluation and may be misdiagnosed; the differential diagnosis includes hepatic focal nodular hyperplasia and interdigitating dendritic cell sarcoma. We herein present a rare case of a young female patient diagnosed with hepatic IPT-like FDC tumor.

\section{Case report}

A 19-year-old woman, with no prior significant disease history, initially presented to the The Second People's Hospital of Changzhou with complaints of abdominal discomfort for 1 month. The $\alpha$-fetoprotein, carcinoembryonic antigen and carbohydrate antigen 19-9 levels were within the normal range. The laboratory values obtained during the initial work-up were as follows: White blood cell count $11.61 \times 10^{9} / 1$, lymphocytes $23.8 \%$, neutrophils $57.1 \%$, hemoglobin level $133 \mathrm{~g} / \mathrm{l}$, total protein $85 \mathrm{~g} / 1$, albumin $46.2 \mathrm{~g} / \mathrm{l}$, total bilirubin $7.7 \mu \mathrm{mol} / 1$, direct bilirubin $2.3 \mu \mathrm{mol} / 1$, aspartate aminotransferase $13 \mathrm{U} / 1$, alanine aminotransferase $10 \mathrm{U} / 1$ and $\gamma$-glutamyltransferase $56 \mathrm{U} / \mathrm{l}$. Ultrasonographic examination revealed a solitary well-defined hypoechoic mass in the liver. Enhanced abdominal computed tomography and magnetic resonance imaging demonstrated a heterogeneous mass in the right hepatic lobe with several low attenuation areas, suggesting necrosis (Fig. 1). No other mass or evidence of lymphadenopathy was present in the abdomen, pelvis or retroperitoneum. Intraoperatively, no lesions were found in the spleen and small bowel, and frozen section pathological examination revealed inflammatory cellular infiltration. The patient underwent hepatic VII segmental resection and the solid nodule was sized $\sim 6 \times 5 \times 4 \mathrm{~cm}$ (Fig. 2A). The postoperative pathological diagnosis was IPT-like FDC tumor with negative margins. Immunohistochemical analysis showed strong reactivity of the tumor cells for CD21, CD35, CD45RO and CD79 $\alpha$. A proportion of the lymphocytes were positive for CD20 (Fig. 2B) and negative for actin, anaplastic lymphoma kinase (ALK), smooth muscle actin- $\alpha$ ( $\alpha$-SMA) and S-100. The infiltrating spindle cells were positive for Epstein-Barr virus (EBV)-encoded small RNAs as determined by in situ hybridization. Finally, the patient was discharged on postoperative day 7 and no metastases or recurrence had developed within a period of 1 year, with normal laboratory values. 

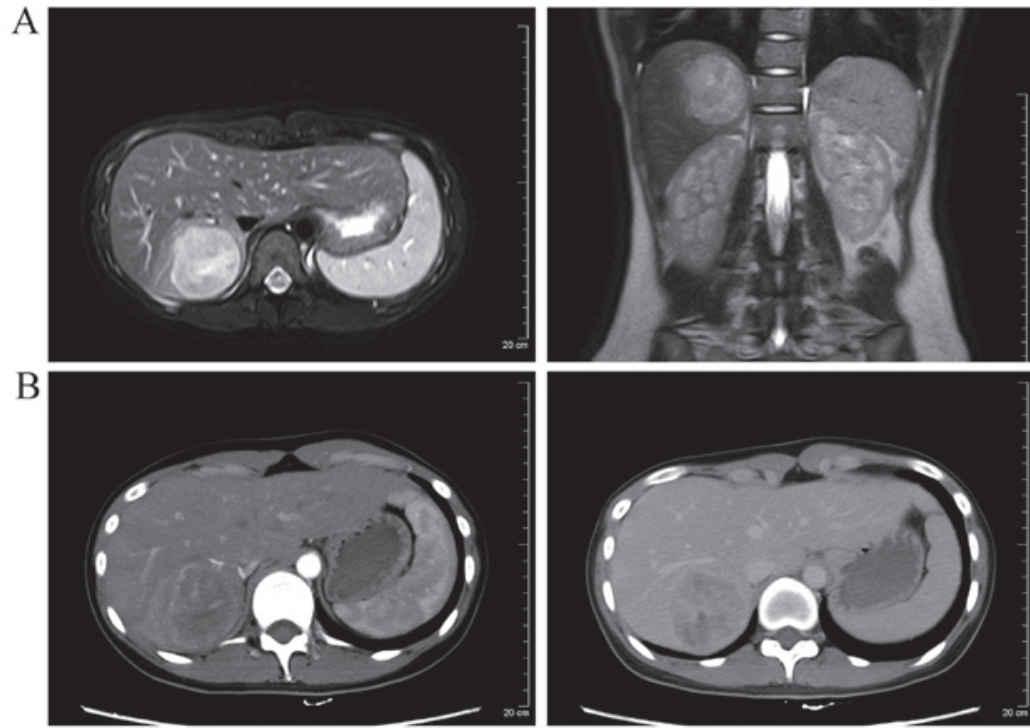

Figure 1. (A) Magnetic resonance images (axial and coronal) and (B) enhanced computed tomography (arterial and venous phase) showing a tumor in the right hepatic lobe.

A
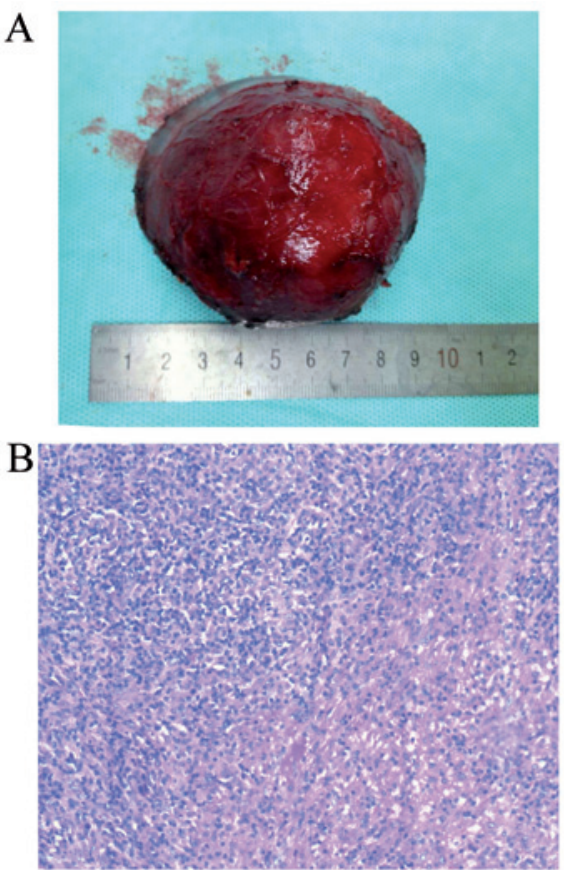
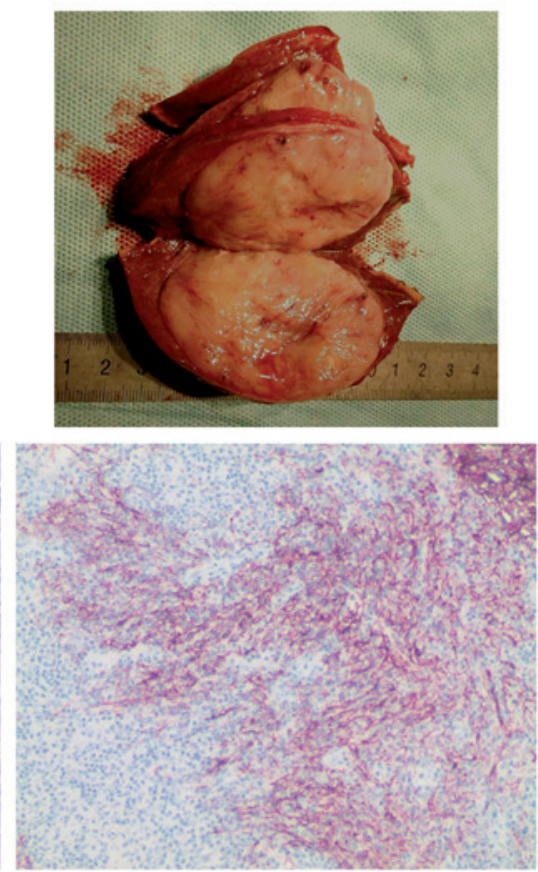

Figure 2. Surgical specimen and pathological analysis. (A) Partial hepatectomy specimen with a complete capsule; the solid nodule was sized $\sim 6 x 5 x 4$ cm. (B) Hematoxylin and eosin staining (left) and immunohischemistry (right) of the tumor showing the CD35+ spindle cells. Original magnification, $\mathrm{x} 100$.

The patient provided a signed informed consent regarding the publication of the case details and associated images.

\section{Discussion}

Hepatic FDC tumor is a rare neoplasm with only 24 cases reported in the English literature to date (4-8). IPT-like FDC tumors of liver are even more rare, and the clinicopathological nature of this type of disease remains unknown. First, the most common presentation of patients with FDC tumors is abdominal pain or weight loss, but IPT-like FDC tumors often grow without clinical symptoms or abdominal discomfort, as was the case in our patient (9). Second, IPT-like FDC tumors always exhibit a marked female predominance (10). Third, IPT-like FDC tumors are strongly associated with the presence of EBV $(11,12)$, although with a lower positivity rate compared with conventional FDC sarcomas (13). On pathological examination, IPT-like FDC tumors cells have a more prominent inflammatory component. In addition, on immunohistochemical staining, the tumor cells are positive for CD21, CD23, CD35 and CD3 (in some cases), and negative for ALK, actin and $\alpha$-SMA, which helps with the differentiation from interdigitating dendritic cell tumors and histiocytic neoplasms (14). Finally, although both IPT-like FDC tumors and conventional 
FDC tumors are treated by surgical resection with no adjuvant therapy, such as radiotherapy or chemotherapy (15), IPT-like FDC tumors exhibit a less aggressive pattern of growth, and fewer recur/metastasize or have a fatal outcome (16).

In conclusion, compared with FDC sarcomas, hepatic IPT-like FDC tumors exhibit a female predominance, association with EBV infection, and generally have a good outcome, with only rare cases of recurrence or metastasis. However, the pathophysiological process underlying this type of disease remains unclear and requires further investigation.

\section{Acknowledgements}

The present study was supported by a grant from the Foundation for Changzhou's High-level Health Talent Cultivation (no. 2016CZBJ007).

\section{References}

1. van Nierop K and de Groot C: Human follicular dendritic cells: Function, origin and development. Semin Immunol 14: 251-257, 2002.

2. Chan J, Pileri SA and Desol G: Follicular dendritic cell sarcoma. IARC Press, Lyon, 2008.

3. Cheuk W, Chan JK, Shek TW, Chang JH, Tsou MH, Yuen NW, $\mathrm{Ng} \mathrm{WF}$, Chan AC and Prat J: Inflammatory pseudotumor-like follicular dendritic cell tumor: A distinctive low-grade malignant intra-abdominal neoplasm with consistent Epstein-Barr virus association. Am J Surg Pathol 25: 721-731, 2001.

4. Martins PN, Reddy S, Martins AB and Facciuto M: Follicular dendritic cell sarcoma of the liver: Unusual presentation of a rare tumor and literature review. Hepatobiliary Pancreat Dis Int 10: 443-445, 2011

5. Bai LY, Kwang WK, Chiang IP and Chen PM: Follicular dendritic cell tumor of the liver associated with Epstein-Barr virus. Jpn J Clin Oncol 36: 249-253, 2006.
6. Granados R, Aramburu JA, Rodríguez JM and Nieto MA: Cytopathology of a primary follicular dendritic cell sarcoma of the liver of the inflammatory pseudotumor-like type. Diagn Cytopathol 36: 42-46, 2008.

7. Nguyen BD, Roarke MC and Yang M: Synchronous hepatic and splenic inflammatory pseudotumour-like follicular dendritic cell sarcomas. Liver Int 35: 1917, 2015.

8. Ma Y, Sun J, Yang C, Yuan D and Liu J: Follicular dendritic cell sarcoma: Two rare cases and a brief review of the literature. Onco Targets Ther 8: 1823-1830, 2015.

9. Chen Y, Shi H, Li H, Zhen T and Han A: Clinicopathological features of inflammatory pseudotumor-like follicular dendritic cell tumor of the abdomen with 10 cases report. Histopathology, 2015.

10. Zhang ZX, Cheng J, Shi QL, et al: [Follicular dendritic cell sarcoma: a clinicopathologic study of 8 cases]. Zhonghua bing li xue za zhi Chinese journal of pathology 37: 395-399, 2008.

11. Selves J, Meggetto F, Brousset P, Voigt JJ, Pradère B, Grasset D, Icart J, Mariamé B, Knecht H and Delsol G: Inflammatory pseudotumor of the liver. Evidence for follicular dendritic reticulum cell proliferation associated with clonal Epstein-Barr virus. Am J Surg Pathol 20: 747-753, 1996.

12. Chen TC, Kuo TT and Ng KF: Follicular dendritic cell tumor of the liver: A clinicopathologic and Epstein-Barr virus study of two cases. Mod Pathol 14: 354-360, 2001.

13. Torres U, Hawkins WG, Antonescu CR and DeMatteo RP: Hepatic follicular dendritic cell sarcoma without Epstein-Barr virus expression. Arch Pathol Lab Med 129: 1480-1483, 2005.

14. Ge R, Liu C, Yin X, Chen J, Zhou X, Huang C, Yu W and Shen X: Clinicopathologic characteristics of inflammatory pseudotumorlike follicular dendritic cell sarcoma. Int J Clin Exp Pathol 7: 2421-2429, 2014.

15. Hu J, Chen LL, Ding BW, Jin DY and Xu XF: Resection is an effective treatment for recurrent follicular dendritic cell sarcoma from retroperitoneum: Unusual presentation of a rare tumor. Int J Clin Exp Med 8: 8218-8221, 2015.

16. Pang J, Mydlarz WK, Gooi Z, et al: Follicular dendritic cell sarcoma of the head and neck: Case report, literature review, and pooled analysis of 97 cases. Head Neck, 2015. 